\title{
Esboço Para Um Pensamento da Diferença E Do Devir Deficiente Na
}

\section{EDUCAÇÃO}

\author{
Rodrigo Barbosa Lopes ${ }^{1}$ \\ Universidade Estadual Paulista Júlio de Mesquita Filho - UNESP
}

\begin{abstract}
Resumo
Propomos neste artigo elaborar o esboço de uma crítica e de uma clínica para o pensamento da diferença e do devir deficiente na reflexão filosófica sobre a educação. $\mathrm{O}$ caminho escolhido passa pela análise de conceitos como diferença, devir, ontologia e acontecimento, apoiando-nos especificamente nas filosofias da diferença de Foucault e de Deleuze que aprofundaram notavelmente o diagnóstico da atualidade filosófica dessas noções. Reconhecemos, igualmente, que o estudo dos modos de problematização é a opção metodológica que um trabalho filosófico sobre a deficiência deve se empenhar em fazer para promover uma ontologia do devir deficiente, a qual considera a deficiência não mais, ou apenas, como objeto de um saber científico e pedagógico, mas como problematização das diferenças e emissão de singularidades irredutíveis ao regime do Mesmo, do Idêntico ou do Semelhante. Apresentamos sumariamente três alternativas ou possibilidades para se firmar na educação uma ontologia e uma política da diferença e do devir deficiente: reverter o platonismo ou conquistar para o devir uma arte das superfícies; propor que a reorganização do trabalho pedagógico da escola inclusiva se inscreva no domínio das práticas; e pensar a ontologia do devir deficiente sob o signo do acontecimento. Esperamos, por fim, que este trabalho contribua para aprofundar o estudo da filosofia da educação sobre a analítica da deficiência, da produção das diferenças e das práticas de inclusão na atualidade.
\end{abstract}

Palavras-chave: acontecimento; diferença; devir deficiente; ontologia; problematização.

\section{OUTLINE FOR A THOUght OF DifFERENCE AND OF BECOMING-DisABLED IN EDUCATION}

\begin{abstract}
We propose in this paper to draw the outline of a review and a clinic for the thinking of difference and of becoming-disabled in philosophical reflection on education. The chosen path goes through the analysis of concepts such as difference, becoming, ontology and event, relying specifically on Foucault's and of Deleuze's philosophies of difference, that notably deepened the diagnosis of philosophical currentness of these notions. We recognize, equally, that the study of modes of problematization is the methodological option that a philosophical work about deficiency should strive to promote an ontology of the becoming-disabled, which considers the disability no more, or just as the object of a scientific and pedagogical knowledge, but as problematization of differences and emission of singularities irreducible to the regime of Same, of Identical or of Similar. We summarily present three alternatives or possibilities to establish in education an ontology and politics of difference and of becoming-disabled: reversing the Platonism or conquer for the becoming an art of surfaces; proposing that the reorganization of the pedagogical work of the inclusive school sign up on the domain of practices; and thinking of the ontology of becoming-disabled under the sign of the event. We hope, finally, that this work
\end{abstract}

\footnotetext{
${ }^{1}$ E-mail: amitiphi@yahoo.com.br 
contributes to deepen the study of philosophy of education on the analytic of disability, of production of differences and of practices of inclusion today.

Keywords: event; difference; becoming-disabled; ontology; problematization.

\section{Esbozo Para Un Pensamiento de Diferencia y do DeVenir Deficiente EN EDUCACIÓN}

\section{Resumen}

Nos proponemos en este trabajo elaborar el esbozo de una crítica y de una clínica para el pensamiento de la diferencia y del devenir deficiente en la reflexión filosófica sobre la educación. El camino elegido pasa por el análisis de conceptos tales como diferencia, devenir, ontología y acontecimiento apoyándonos específicamente en las filosofías de Foucault y Deleuze que profundizaron significativamente el diagnóstico de la realidad filosófica de estas nociones. También reconocemos, igualmente, que el estudio de los modos de problematización es la opción metodológica que una obra filosófica sobre la deficiencia debe esforzarse para promover una ontología de lo devenir deficiente, que ve a la deficiencia ya no, o no sólo como el objeto de un conocimiento científico y pedagógico, sino como problematización de las diferencias y emisión de singularidades irreducibles al régimen de lo Mismo, de lo Idéntico o Semejante. Presentamos sucintamente tres alternativas o posibilidades para establecer en la educación una ontología y una política de la diferencia y del devenir deficiente: invertir el platonismo o conquistar para el devenir un arte de superficies; proponer que la reorganización de la labor educativa de la escuela inclusiva se inscriba en el campo de las prácticas; y pensar en la ontología del devenir deficiente bajo el signo del acontecimiento. Esperamos, por último, que este trabajo contribuya a profundizar el estudio de la filosofía de la educación sobre la analítica de la deficiencia, la producción de las diferencias y de prácticas de inclusión en la actualidad.

Palabras clave: acontecimiento; diferencia; devenir deficiente; ontología; problematización. 


\section{Notas introdutórias}

Escrever é um caso de devir, sempre inacabado, sempre em via de fazerse, e que extravasa qualquer matéria vivível ou vivida. É um processo, ou seja, uma passagem de Vida que atravessa o vivível ou o vivido. (Gilles Deleuze, "A literatura e a vida").

Não são incomuns as ocasiões em que as experiências de pensamento que a escrita nos proporciona realizar nos permitem lançar, a cada vez que seu aparecimento nos anima com um fôlego renovado, a pergunta por aquilo que estamos em vias de fazer, pelo sentido do que fazemos quando o ofício ou a tarefa é escrever, por exemplo, sobre educação. Mas a escrita também nos oferece uma permanente disponibilidade, ou, talvez, um tipo de disposição frente à educação, que não é seguramente a fixação de um ponto de esclarecimento e verdade para saber, com certeza, o que se deve escrever, nem, antecipadamente, a que lugar é preciso chegar para, então, concluir, ao final da empreitada intelectual, que realizamos o percurso com êxito. As dimensões do devir e da experiência da escrita dispensariam tais pretensões. Ou seja, se preferimos pensar com Deleuze (1997) que a escrita é inseparável do devir, de um trabalho minoritário do pensamento, como linha de fuga às formas hegemônicas da representação e da verdade, então a escrita em educação deve ser primeiramente uma abertura de pensamento à vida, ao que pode instituir, no pensamento, o plano intensivo e conquistar para ele a “zona de vizinhança, de indiscernibilidade ou de indiferenciação" (DELEUZE, 1997, p. 11) com a qual é possível fazer a experiência da gênese do pensar no pensamento. E é nesse ponto precisamente que Deleuze não nos deixa esquecer o fundamental, que "[...] no caminho que leva ao que existe para ser pensado, tudo parte da sensibilidade. Do intensivo ao pensamento, é sempre por meio de uma intensidade que o pensamento nos advém. " (1976, p. 188). Fazer, assim, a experiência do encontro do pensamento com aquilo que o força a pensar, o signo, com o que existe para ser pensado, é a condição de fazer a experiência da escrita e do devir como um ato de pensamento. A esse respeito, terá dito Deleuze em Proust et les signes "[...] $\mathrm{O}$ ato de pensar não decorre de uma simples possibilidade natural; 
é, ao contrário, a única criação verdadeira. A criação é a gênese do ato de pensar no próprio pensamento." (1987, p. 96).

$\mathrm{Na}$ apresentação ao público brasileiro da tradução da obra Empirisme et subjectivité, de Gilles Deleuze, vemos Luiz Orlandi afirmar que "em vez de praticar exclusões que acabam reiterando falsas noções de progresso em filosofia, um dos mais fecundos interesses dos estudos filosóficos é participar atentamente desse cruzamento de idéias díspares, desvelando paisagens inesperadas nessa vasta síntese disjuntiva que é o pensamento conceitual. " (2001, contracapa). Concordamos, do mesmo modo, que em face da constelação conceitual que nos abre um campo variado de temas e possibilidades de leitura, escrever tem a ver talvez com um exercício específico de pensamento: desbravar a disponibilidade da filosofia é propiciar o enfrentamento com a tradição, lançar o desafio de trabalhar os saberes formalizados, revisitar os autores e revisar os conhecimentos acumulados em face das novas exigências que a atualidade nos impõe. Tudo isso é importante, porque sem esse trabalho do pensamento, ao mesmo tempo solitário e povoado de conceitos e de experiências, não teríamos uma palavra a mais a dizer sobre aquilo que ele pode ter de novidade, de surpresa; mas também e, principalmente, porque é nesta viragem que o novo salta aos nossos olhos, que a criação em filosofia é mais uma vez possível. É nesse sentido que compreendemos o que disse Deleuze a respeito dos estoicos: “[...] O gênio de uma filosofia se mede em primeiro lugar pelas novas distribuições que impõe aos seres e aos conceitos. " (1969, p. 15).

Nisso há uma questão singular importante que queremos elucidar antes de iniciar a análise do tema da problematização da diferença e do devir deficiente: o exercício da escrita, a produção da escrita na educação. Talvez seja, na verdade, uma oportunidade para pensar, isto é, que nos faça pensar no aspecto formativo da escrita - da produção do pensamento em educação -, não exclusivamente acerca do aprendizado de conteúdos e que no mais resultaria numa ampliação do conhecimento, importante é claro, mas quanto à atividade mesma da escrita, de certa função da escrita, precisamente dupla. A primeira diz respeito à elaboração 
do texto, de seu conteúdo e que se conforma à investigação de temas, ao trabalho muito particular de manutenção e ampliação do conhecimento. Outra se refere à produção da escrita, ao exercício do pensamento sobre ele mesmo, que, nas palavras de Michel Foucault, “[...] reativa o que ele sabe, torna presentes um princípio, uma regra ou um exemplo, reflete sobre eles, assimila-os, e assim se prepara para enfrentar o real. " (2001, p. 1236). É nesse sentido específico que sugerimos que as reflexões aqui indicadas sobre as possibilidades de propor para a educação um pensamento da diferença e do devir deficiente sejam retomadas e convidamos o leitor a pensar, ainda que brevemente, sobre a singularidade de uma política da escrita na educação, de escrita pedagógica. Indicamos três máximas ou axiomas - ao modo como Spinoza fazia a demonstração geométrica dos princípios da Ética (2010) - que nos permitem pensar sobre as diferenças e singularidades que habitam as experiências educativas e a escrita pedagógica: primeiro, que a experiência, e não a verdade, é o que dá sentido à escrita; segundo, que a experiência, e não a verdade, é o que dá sentido à educação; e, por fim, que a instrução é como a liberdade: ela não se dá, conquista-se. Mas tudo isso sob o signo da experiência, do devir, da transformação... não da verdade.

Três indicações singulares para uma política da escrita na educação. Elas estão anunciadas na Coleção Educação: Experiência e Sentido, editada pela Editora Autêntica e comentadas pelos coordenadores da coleção Jorge Larrosa e Walter Kohan, que as apresentaram brevemente, mas com a brevidade de uma inteligência bem trabalhada, com palavras acertadamente escolhidas. Neste caso, essas palavras prefaciavam O mestre ignorante, de Jacques Rancière (2007), uma obra cuja relevância e novidade surpreendem até mesmo o leitor mais exigente. Mas, nosso propósito aqui não é de comentá-las, menos ainda explicá-las, porque tudo o que menos desejamos à educação é que a ordem explicadora instalada em nossa sociedade pedagogizada tenha um futuro ainda mais promissor do que seu passado recente e cujos efeitos ainda se fazem sentir no presente. A figura que desejamos para a educação é a do mestre emancipador e a que preterimos, a do mestre explicador. Já há explicações demais... é preciso silenciá-las, fazer ouvir o 
esboço para um pensamento da diferença e do devir deficiente na educação

que Manuel de Barros (2015) encerra em seus poemas: explicar afasta as falas da imaginação. Nisso há novidade e criação, porque se investe na invenção da experiência educativa e não na explicação das verdades sobre a educação. A escolha a ser feita é fundamental e necessária. A esse propósito, Rancière escreveu no prefácio à edição brasileira:

Ele [Joseph Jacotot] preveniu: a distância que a Escola e a sociedade pedagogizada pretendem reduzir é aquela de que vivem e que não cessam de reproduzir. Quem estabelece a igualdade como objetivo a ser atingido, a partir da situação de desigualdade, de fato a posterga até o infinito. A igualdade jamais vem após, como resultado a ser atingido. Ela deve sempre ser colocada antes. [...] Instruir pode, portanto, significar duas coisas absolutamente opostas: confirmar uma incapacidade pelo próprio ato que pretende reduzi-la ou, inversamente, forçar uma capacidade que se ignora ou se denega a se reconhecer e a desenvolver todas as consequências desse reconhecimento. $\mathrm{O}$ primeiro ato chama-se embrutecimento e o segundo, emancipação. (2007, p. 11-12).

E nós, o que pretendemos? Ainda sobre a escrita pedagógica, ou da escrita como exercício do pensamento, gostaríamos de dizer algumas palavras a mais. Foucault precisou que:

[...] a escrita está associada ao exercício de pensamento de duas maneiras diferentes. Uma toma a forma de uma série "linear"; vai da meditação à atividade da escrita e desta ao gumnazein, isto é, à preparação na situação real e à experiência: trabalho de pensamento, trabalho pela escrita, trabalho na realidade. A outra é circular: a meditação precede as notas as quais permitem a releitura que, por sua vez, revigora a meditação. Em todo caso, seja qual for o ciclo de exercício em que ela ocorre, a escrita constitui uma etapa essencial no processo para o qual tende toda a askêsis: a saber, a elaboração dos discursos recebidos e reconhecidos como verdadeiros em princípios racionais de ação. (2001, p. 1236-1237).

Esse fragmento é parte de um texto mais longo, intitulado L'écriture de soi e publicado pela primeira vez em 1983, o qual faz parte de uma série de estudos sobre as artes de si mesmo: neste caso, a estética da existência na cultura grecoromana dos dois primeiros séculos da era cristã. Mas são duas as formas de escrita analisadas nesse texto por Foucault: os hupomnêmata e a correspondência. Quanto à primeira, que mais se aproxima do convite que fazemos ao leitor para se lançar em busca de novas experiências de pensamento, um aspecto nos convida à reflexão: os hupomnêmata eram cadernos em que se inventariavam citações, fragmentos de obras, de assuntos lidos, ouvidos ou simplesmente pensados, de exemplos e ações, com a finalidade de permitir a reflexão posterior e, com isso, a 
constituição de certo saber preciso: “[...] Eles constituíam uma memória material das coisas lidas, ouvidas ou pensadas; eles as ofereciam assim como um tesouro acumulado para a releitura e a meditação posteriores. Formavam também uma matéria prima para a redação de tratados mais sistemáticos [...]. " (FOUCAULT, 2001, p. 1237); mas também e principalmente para a constituição de si: “[...] Tal é o objetivo dos hupomnêmata: fazer do recolhimento do logos fragmentário e transmitido pelo ensino, pela escuta ou pela leitura um meio para o estabelecimento de uma relação de si consigo mesmo tão adequada e completa quanto possível." (FOUCAULT, 2001, p. 1239).

Em Deleuze reconhecemos, igualmente, essas variações do devir e da experiência da escrita na estranha disponibilidade do pensamento filosófico. Primeiramente, quando questionado sobre a razão de escrever um livro a respeito de Foucault, dois anos após a sua morte - haja vista já ter comentado outras vezes a obra de seu amigo - e se agora haveria ou não algo de simbólico na publicação desse livro, vemos Deleuze responder que seus esforços estão concentrados em conhecer a lógica de pensamento de Foucault que "[...] não cessa de crescer em dimensões, e nenhuma das dimensões está contida na precedente. Então o que o força a lançar-se em tal direção, a traçar tal caminho sempre inesperado? " (1992, p. 118). O que interessava a Foucault e que foi oportunamente mostrado por Deleuze é a renovação do pensamento. A esse respeito, o próprio Deleuze reiterou o quanto o pensamento contemporâneo é devedor da filosofia de Nietzsche e, na esteira aberta por este filósofo, encontramos Foucault, que fez de sua própria filosofia um ato de pensamento; isto é, uma experimentação e uma problematização do pensamento. Como disse Deleuze, no livro que com Foucault ele gostaria de ter escrito:

[...] Certamente, uma coisa perturba Foucault, e é o pensamento. "Que significa pensar? O que se chama pensar?" - a pergunta lançada por Heidegger, retomada por Foucault, é a mais importante de suas flechas. Uma história, mas do pensamento enquanto tal. Pensar é experimentar, é problematizar. O saber, o poder e o si são a tripla raiz de uma problematização do pensamento. (1988, p. 124).

O que estas páginas têm de propositivo há que contribuir para ampliar as reflexões sobre a elaboração de um pensamento da diferença e do devir deficiente 
no campo da educação. Mas desejamos sobretudo que este texto seja portador de questionamentos, ponto de partida para mais discordâncias do que concordância, mais divergências do que convergências. No mínimo, pensar assim causa certa estranheza, mas, de que outro modo seria possível surgir a novidade que nos faz avançar na descoberta de outras formas de pensamento e trabalho pedagógico senão pela diferença que graceja às portas de nosso mundo de ideias apaziguadas da representação? Um trabalho, falava Foucault a respeito de si mesmo, quando não é, ao mesmo tempo, uma tentativa de modificar o que se pensa e mesmo o que se é, não é muito interessante (2001, p. 1487). Nesse sentido, é que pensamos a educação sob o signo da experiência: ela é alguma coisa da qual nós mesmos saímos transformados. E Foucault ainda nos lembra belamente que: “Quando escrevemos livros, desejamos que estes modifiquem inteiramente tudo aquilo que pensávamos e que, no final, nos percebamos inteiramente diferentes do que éramos no ponto de partida. " (2001, p. 1550). Nesse sentido, partilhamos todos fundamentalmente a mesma condição, o mesmo status: somos amigos da igualdade de inteligências. Porém, permanece a pergunta: $O$ quanto nós mudamos? O quanto estamos dispostos a mudar?

\section{Problematização da diferença e do devir deficiente como uma ontologia e um éthos}

Antes, porém, de apresentar uma a uma as partes que compõem a reflexão consignada nas páginas deste artigo, traçamos sumariamente o plano de análise ou a crítica em defesa do aprofundamento do pensamento da diferença e do devir deficiente na educação. Admitimos que o estudo dos modos de problematização é a opção metodológica que um trabalho filosófico sobre a deficiência deve se empenhar em fazer para promover uma ontologia do devir deficiente, a qual considera a deficiência não mais, ou apenas, como objeto de um saber científico e pedagógico, mas como problematização das diferenças e emissão de singularidades irredutíveis ao regime do Mesmo, do Idêntico ou do Semelhante. O caminho escolhido passa pela análise de conceitos como diferença, devir, ontologia e acontecimento, apoiando-nos especificamente nas filosofias da 
diferença de Foucault e de Deleuze que aprofundaram notavelmente o diagnóstico da atualidade filosófica dessas noções. A filosofia como diagnóstico da atualidade, ao abordar o tema da diferença e do devir segundo uma lógica do acontecimento, permite considerar o devir deficiente em três linhas de atuação de uma analítica das práticas de constituição da subjetividade: como uma crítica prática; arqueológica no método e genealógica na finalidade; e uma atitude experimental. Dessas indicações singulares de alcance geral, podemos extrair três alternativas ou possibilidades para se firmar na educação uma ontologia e uma política da diferença e do devir deficiente, apresentadas ao final do artigo: $\left(1^{\mathrm{a}}\right)$ reverter o platonismo ou conquistar para o devir uma arte das superficies; $\left(2^{\mathrm{a}}\right)$ propor que a reorganização do trabalho pedagógico da escola inclusiva se inscreva no domínio das práticas; $\left(3^{\mathrm{a}}\right)$ e pensar a ontologia do devir deficiente sob o signo do acontecimento. Esperamos que, ao final, este trabalho contribua para aprofundar o estudo da filosofia da educação sobre a analítica da deficiência, da produção das diferenças e das práticas de inclusão na atualidade.

Contudo, como é preciso escolher um começo, partimos das coordenadas de um problema específico que tem marcado de forma permanente a cultura geral. O problema diagnosticado é que a deficiência, para uma sociedade biopolítica atual, está em profundidade e largura escrutinizada pelas condições nosopolíticas de classificação dos indivíduos entre normalidade e anormalidade ${ }^{2}$. No tocante à multiplicação das artes de governar, demonstrada em trabalhos oriundos dos cursos de Foucault no Collège de France 3 , por exemplo, vemos se prolongar na condução da vida dos deficientes e dos saberes sobre a deficiência a prevalência dos discursos e práticas de normalização - biopolíticas, portanto, - aplicados em conjunto e estrategicamente como uma maquinaria terrível de análise, classificação e diferenciação dos sujeitos segundo critérios científicos, sociais e até pedagógicos. Nesse particular, é relevante apontar um trabalho em que a hipótese

2 É o que é possível entrever, por exemplo, a partir de uma leitura atenta do World Report on Disability (2011), elaborado pela Organização Mundial de Saúde. Nele, deixa-se entrever, inclusive, o que pode creditar ao pensamento uma mudança radical de perspectiva: "Disability is part of the human condition". (2011, p. 3).

${ }^{3}$ A título de exemplo, citam-se os cursos de 1974-1975 a 1978-1979: Os anormais (2001); Em defesa da sociedade (1999); Segurança, território, população (2008b); e Nascimento da biopolítica (2008a). 
de uma ontologia do devir deficiente é desenvolvida na esperança de produzir, assim entendemos, a liberação da deficiência da falsa alternativa do normal e do anormal. Em Governo da infância e ontologia política do devir deficiente: implicações para a educação, Carvalho assume essa ideia, "[...] na perspectiva a indicar que a nossa condição existencial é em si e no que é um modo de ser atravessado pela deficiência em virtualidade." (2014, p. 3). A proposta de um plano de consistência virtual da deficiência é bastante poderosa, mas gostaríamos de pensar que ela seja, logo de partida, um modo de promover uma ética da afirmação da deficiência. Nos colocamos, portanto, sob o signo dessa mesma esperança, e apresentamos a seguir uma alternativa para o aprofundamento da noção de ontologia do devir deficiente na educação.

A registros próprios de um estudo dos modos de problematização, tal como Foucault (2001, p. 1381-1397; p. 1410-1417; p. 1487-1497) o propunha a partir de seus últimos trabalhos, com a filosofia parece ocorrer o seguinte: as perguntas não param de saltar aos olhos de quem as ouve, e eclipsam o pensamento quando se tem a impressão de que no próximo instante um esclarecimento está em vias de ocorrer. Com efeito, tão importante quanto o movimento que elas impõem ao pensamento, porquanto se afirmam como signos de ruptura e invenção, é o modo como, enfim, elas põem em questão a natureza extraproposicional dos problemas: elas operam por uma proliferação de ideias, crescem por dimensões e estabelecem zonas de vizinhança nas quais se evidenciam o jogo das influências, as alianças e as misturas, o crescimento em dimensões de um pensamento que não opera por generalidade, mas por diferenciações; enfim, o jogo da multiplicidade. Qual é, pois, a questão que exerce esse efeito aglutinador das perguntas que se oferecem como signos do pensamento? A questão é a problematização do pensamento, isto é, o exercício filosófico do pensamento como produção da diferença e do devir.

Foucault talvez tenha sido o filósofo que mais bem compreendeu que a tarefa de uma filosofia do porvir deveria assumir as feições de um trabalho crítico do pensamento como diagnóstico da atualidade, o que ele apropriadamente chamou de ontologia do presente (2001, p. 1506) ou de ontologia crítica de nós mesmos 
(2001, p. 1396), e que, enquanto atividade filosófica de investigação do presente, de análise da constituição histórica de nossa subjetividade, apenas poderia se apresentar na forma de uma atitude crítica como problematização do pensamento. No mais, esta seria a única contribuição que Foucault poderia prometer a uma filosofia então lastreada por um estudo dos modos de problematização: a possibilidade do enfretamento com as questões, com as práticas históricas e com os acontecimentos que agem nos processos de constituição de nossa subjetividade; e, por esse motivo, uma ontologia histórica sobre a nossa constituição como sujeitos de experiência.

O próprio Foucault reconheceu, ao fazer uma referência remissória às suas publicações, que a noção que unificava todos os estudos por ele realizados desde Histoire de la folie é a de problematização, embora ele não a tivesse ainda isolado suficientemente, tal como ele viria a fazer, depois, nos trabalhos da década de 1980. Em Le souci de la vérité, por exemplo, Foucault esclareceu que:

Problematização não quer dizer representação de um objeto preexistente, nem tampouco a criação pelo discurso de um objeto que não existe. É o conjunto das práticas discursivas ou não discursivas que faz alguma coisa entrar no jogo do verdadeiro e do falso e o constitui como objeto para o pensamento (seja sob a forma da reflexão moral, do conhecimento científico, da análise política, etc.). (2001, p. 1489).

Com efeito, falávamos anteriormente que Deleuze ${ }^{4}$ nos fez lembrar algo de fundamental no estudo que dedicara à compreensão da filosofia de Michel Foucault, e o fez de um modo tal que até parecia revelar algo que Foucault tivesse dito secretamente, ao modo de uma confissão entre amigos, que apesar das idas e vindas sobre as questões do sujeito com relação à verdade, ao poder e consigo, era o pensamento, o exercício do pensamento como problematização e experimentação

\footnotetext{
${ }^{4}$ Em outro trabalho, Conversações (1992), comentando a confirmação indispensável para a sua própria filosofia o que ele escrevera em Foucault (1988), Deleuze explicou o seguinte: “O livro que fiz não é de história da filosofia, é um livro que eu gostaria de ter feito com ele, com a idéia que tenho dele e com minha admiração por ele. " (1992, p. 188). Por esse motivo, e escrevendo de uma forma livre, quase experimental, completou o que mais despertava nele a admiração por Foucault: "[...] Ele suscitava medo, isto é, só com sua existência impedia a impudência dos imbecis. Foucault preenchia a função da filosofia definida por Nietzsche, 'incomodar a besteira'. Nele, o pensamento é como um mergulho que traz sempre algo à luz. É um pensamento que faz dobras, e de repente se distende como uma mola. No entanto, não creio que Leibniz tenha tido alguma influência especial sobre ele. Mas uma frase de Leibniz lhe convém particularmente: eu acreditava ter chegado ao porto, mas fui lançado de volta ao mar. Os pensadores como Foucault procedem por crises, abalos, há neles algo de sísmico." (p. 188).
} 
esboço para um pensamento da diferença e do devir deficiente na educação

que interessava a Foucault ${ }^{5}$ e que, ademais, o levaria a esclarecer, sobretudo nos dois últimos anos de sua vida, que seu trabalho filosófico tinha a ver precisamente com isso: "O estudo dos (modos de) problematizações (isto é, do que não é constante antropológica nem variação cronológica) é, portanto, a maneira de analisar, em sua forma historicamente singular, as questões de alcance geral." (FOUCAULT, 2001, p. 1396).

É particularmente relevante considerar o modo com o qual ele caracteriza a tarefa da Filosofia contemporânea e a sua própria filosofia, ou seja, como uma atitude filosófica ou um modo de interrogação crítica sobre o presente que põe em evidência ao menos duas questões fundamentais: $O$ que é a nossa atualidade? Qual o campo atual das experiências possíveis? A definição desta atividade filosófica como diagnóstico da atualidade tem, com efeito, a garantida de sua "coerência metodológica" com base num estudo ao mesmo tempo arqueológico e genealógico das práticas históricas de constituição dos campos de experiência e de nossa subjetividade; uma "coerência teórica" lastreada pelas formas historicamente singulares com as quais se tem problematizado as relações gerais de nosso pertencimento ao presente, nelas consideradas igualmente as nossas relações com a verdade, com a política e a moral; e ainda uma "coerência prática" resultante da confrontação da reflexão filosófica, de caráter histórico-crítico, com o campo real das experiências e das práticas concretas. Desse modo, Foucault esclarece que é preciso considerar a ontologia crítica de nós mesmos:

[...] não certamente como uma teoria, uma doutrina, nem mesmo como um corpo permanente de saber que se acumula; é preciso concebê-la como uma atitude, um éthos, uma via filosófica em que a crítica do que somos é ao mesmo tempo análise histórica dos limites que nos são colocados e prova de sua ultrapassagem possível. (2001, p. 1396).

\footnotetext{
${ }^{5}$ Falamos, evidentemente, a partir de Deleuze e de seu ponto de vista. Mas o próprio Foucault nos autoriza a inferir de seus últimos trabalhos, destacadamente What is Enlightenment?, Polémique, politique et problématisations; e Le souci de la vérité, todos datados de 1984, que a atividade filosófica como o estudo dos modos de problematização norteara as suas escolhas e a conduta em face dos desafios supervenientes de seu problema geral de pesquisa. Por força desse esclarecimento, se o trabalho filosófico de Foucault se volta, pois, constantemente ao problema das relações entre o sujeito, a verdade e a constituição da experiência (FOUCAULT, 2001, p. 1550), tanto mais importaria destacar a questão do sujeito e as práticas históricas de sua constituição como um problema central de sua filosofia.
} 
Além daquelas duas expressões, Foucault utiliza também ontologia da atualidade (2001, p. 1507) e é quanto a esta última indicação que o vemos, finalmente, afirmar: “[...] a filosofia como problematização de uma atualidade e como interrogação pelo filósofo desta atualidade da qual ele faz parte e com relação à qual ele tem que se situar [...]. " (2001, p. 1499-1500).

A noção de atualidade está empregada, desse modo, para sublinhar como um acontecimento não somente engendra toda uma série de discursos, de práticas e de comportamentos, mas se prolonga, em noutro sentido, até nós. Por um lado, diagnosticar a atualidade consistiria em reconhecer o acontecimento sob o signo do qual nós mesmos aparecemos, nós mesmos somos, e, por outro, qual o acontecimento que ainda continua a nos atravessar, isto é, o qual nós repetimos em nossa atualidade. “[...] A passagem da arqueologia à genealogia será para Foucault a ocasião de acentuar ainda esta dimensão de prolongamento da história no presente. " (REVEL, 2009, p. 08). Mas há um segundo emprego da noção de atualidade, o qual está estritamente ligado aos dois artigos escritos por Foucault sobre o texto de Kant "O que é o Iluminismo? "6. A atividade de diagnóstico consiste, neste caso, em colocar filosoficamente a questão do presente, a questão de nossa atualidade. No caso de Foucault, como no de Kant, colocar a questão do pertencimento à sua própria atualidade é uma forma de interrogá-la como um acontecimento do qual teríamos de dizer o sentido e a singularidade, e, por outro lado, colocar a questão do pertencimento a um "nós" correspondente a esta atualidade (2001, p. 1499-1500).

Embora as noções de atualidade e presente sejam ordinariamente empregadas no mesmo sentido, uma diferença se faz notar na análise de Foucault entre o que, por um lado, nos precede e continua a persistir no tempo presente, ao modo da repetição de uma regularidade, e o que surge, doutro modo, como uma ruptura nesta regularidade epistêmica do presente ao qual nos vinculamos e da periodização que ele engendra. Esta irrupção do novo, da diferença como

\footnotetext{
${ }^{6}$ Aludimos aqui a dois trabalhos de Foucault publicados no ano de 1984, What is Enlightenment? e Qu'est-ce que les Lumières?, e reunidos em um único volume por ocasião da publicação, na França, pelas Éditions Gallimard, de Dits et Écrits (2001).
} 
singularidade, o que Foucault tanto quanto Deleuze chamam de acontecimento, torna-se, com efeito, o que caracteriza especificamente a atualidade e a distingue, singularmente, do presente. “[...] O presente, definido por sua continuidade histórica, não é fraturado por nenhum acontecimento: ele apenas pode bascular e se rompe dando lugar à instalação de um novo presente. " (REVEL, 2009, p. 10). Nesse sentido, se a questão filosófica tem por objeto o que é este presente ao qual pertencemos, ela tem por tarefa o objetivo de determinar a diferença que no presente é preciso reconhecer, distinguir e interpretar entre todos os outros elementos: a irrupção de um acontecimento como singularidade histórica, que revela ao presente sua diferença interna e que o pensamento experimenta como atualidade.

Em síntese, pensar pelo acontecimento é essa maneira de analisar em sua forma historicamente singular questões de alcance geral. Assumindo esta prática como tarefa e motivo para uma reflexão filosófica na educação, interrogar a deficiência em termos de singularidade definirá, pois, para o tempo presente, o esboço do que bem se poderia chamar uma ontologia do devir deficiente. Esta é a diferença que é preciso reconhecer entre uma história das práticas de normalização, que institui, por exemplo, a validade dos discursos nosopolíticos, e uma ontologia do devir como atitude crítica em vista de fazer aparecer a diferença onde ela foi preterida. Tal ontologia apenas poderia ser um diagnóstico dos discursos científicos, políticos e pedagógicos sobre a deficiência na atualidade, ou seja, uma crítica prática, ao mesmo tempo histórica e metodológica, da pertinência da reflexão filosófica sobre a deficiência como singularidade e como motivo para uma tarefa de renovação do pensamento.

Propor a redistribuição dos saberes sobre a deficiência segundo uma problematização das diferenças é, assim, colocar no primeiro plano de análise não a ação normalizadora de classificação entre indivíduos normais e deficientes, mas o aparecimento do devir como um signo de ruptura e de descontinuidade em divergência ao que se pode extrair de uma imagem nosospolítica do pensamento. Consiste, portanto, em admitir o devir deficiente como a irrupção do imprevisto e 
do extraordinário, como signo de diferença e prática de acontecimentalização (FOUCAULT, 2001, p. 842-844); em uma palavra, como ontologia. Porém, por “ontologia" não se deve entender pesquisa pela essência ou pela realidade formal do ser, mas como uma interrogação sobre a constituição histórica e crítica de nossa subjetividade; tanto quanto, aliás, é também uma interrogação fundamental sobre a constituição dos campos de experiência a partir dos quais construímos as soluções para os problemas que solicitam um exame crítico, mas que, por outro lado, dirige-se ao estudo das práticas e dos discursos com que se nos apresentam, na sua forma historicamente singular, os problemas de alcance geral. Fazer, pois, uma analítica da deficiência não é registar os modos através dos quais, e ao longo do tempo, um objeto novo surgiu para o saber científico, a deficiência, mas deslocar para a superfície, para um primeiro plano de análise, as singularidades como reintrodução do novo, do intensivo e do extraordinário no pensamento e na vida; isto é, a experiência de pensarmos pela diferença, e a diferença de pensarmos pelo signo do acontecimento. Com isso, não é mais a verdade o valor indelével do pensamento, mas o sentido, a vontade de produzir a diferença onde só se encontram normalidades. É, enfim, uma resposta à pergunta: qual o campo atual das experiências possíveis?

É nesse sentido que um estudo dos modos de problematização das diferenças tomará a forma de uma ontologia histórico-crítica de nós mesmos, de uma ontologia do devir deficiente. E é nesse sentido também que a filosofia da educação, ao se debruçar sobre o problema da deficiência, deverá pensar o devir deficiente a partir de um duplo movimento: além de tornar manifesto criticamente o nosso pertencimento a essa imagem normalizada da deficiência e da inclusão, deve permitir que se realize uma crítica histórico-prática dos limites que dela se nos impõe e como prova de sua ultrapassagem possível. Assim, fazer da problematização das diferenças uma ontologia do devir deficiente é fazer o pensamento não operar por generalidade, mas por séries distintas de diferenciação. Diferentemente da imagem desigual sob o signo da qual os deficientes aparecem, a qual impõe às diferenças a repetição de uma regularidade, 
pensar a deficiência por meio de uma ontologia do devir é produzir, antes de tudo, uma ruptura epistêmica na regularidade dos discursos científicos e pedagógicos sobre os deficientes, para fazer surgir ali, onde só se encontra a repetição de um traço idêntico, o despontar de feixes de singularidade. A diferença é para a deficiência a própria singularidade.

Para completar o sentido do que propomos, é preciso dizer também que a apresentação da investigação filosófica como diagnóstico da atualidade tem a ver, essencialmente, com a definição de um éthos filosófico como “[...] a reativação permanente de uma atitude; isto é, um éthos filosófico que seria possível caracterizar como crítica permanente de nosso ser histórico. " (FOUCAULT, 2001, p. 1390). Nisso consiste precisamente a proposta de fazer da filosofia um ato de problematização, sem o que não poderíamos reconhecer nos problemas analisados, enquanto signos, a novidade de que eles são portadores, tanto quanto a possibilidade de o exercício do pensamento surgir como uma experimentação. Recordemos, a propósito, que, para os gregos, éthos se trata de uma maneira ou modo de ser do sujeito, de pensar e de conduzir a vida traduzida em costumes, em hábitos fundamentais: seja na forma do comportamento (das decisões pessoais em relação às obrigações e às instituições); seja no âmbito da cultura (como conjunto de ideias, valores ou crenças); seja ainda na forma de uma subjetividade interiorizada (com respeito à vontade, ao desejo, às escolhas). Assim, Foucault define atitude como um modo de relação que concerne exclusivamente à atualidade, isto é, como uma escolha voluntária delineada por um modo de pensar, de sentir, de agir e de conduzir a vida que marca, ao mesmo tempo, o nosso pertencimento a esta atualidade e a tarefa de diagnosticá-la. Enfim, essa atitude deve se traduzir, no presente, como éthos e como ontologia crítica da atualidade. Em What is Enlightenment?, Foucault reativa a importância dessa definição de atitude crítica:

Eu caracterizaria então o éthos filosófico próprio à ontologia crítica de nós mesmos como uma prova histórico-prática dos limites que podemos transpor e, portanto, como trabalho de nós mesmos sobre nós mesmos enquanto seres livres. (2001, p. 1394). 
Pois bem, no intuito de indicar os traços de uma ontologia do devir deficiente em contraposição à prática discursiva nosopolítica e normalizadora, destacamos sumariamente três características que a diferença como éthos, isto é, como ontologia e atitude crítica, singulariza nos sujeitos a respeito do devir e da deficiência, e que passamos a considerar no que elas podem ajudar a esclarecer a tarefa da filosofia da educação de pensar uma ontologia do devir deficiente. Primeiramente, o devir deficiente poderia ser caracterizado como uma atitude limite na forma de uma crítica prática. Se por um lado a crítica consiste na análise dos limites do conhecimento, quanto às condições para que o conhecimento seja verdadeiro, tal como pretendia Kant (2001), por outro, com a ontologia do presente a crítica assume as formas de uma interrogação que reverte a razão negativa em razão prática e positiva: ao invés da questão sobre o universal, o necessário e o obrigatório, a investigação filosófica deve se interrogar sobre o singular, o contingente e o involuntário. “[...] Trata-se, em suma, de transformar a crítica exercida sob a forma de limitação necessária em uma crítica prática sob a forma de uma ultrapassagem possível." (FOUCAULT, 2001, p. 1393).

Uma vez que não mais admitimos a crítica como uma pesquisa das estruturas formais de valor universal, mas como pesquisa histórica dos acontecimentos que continuam a implicar, por meio da constituição de novos campos de experiência, na ontologia histórica de nossa subjetividade, conclui-se a partir disso uma segunda característica para pensar o devir deficiente. Seguindo essas indicações deixadas por Foucault (2001, p. 1393), é uma crítica arqueológica em seu método: ocupa-se dos discursos que articulam o que pensamos, dizemos e fazemos enquanto acontecimentos históricos; portanto, não se trata de uma crítica transcendental, haja vista que não procura estabelecer as condições universais de todo conhecimento verdadeiro. Em noutro sentido, a crítica é genealógica em sua finalidade, isto é, no sentido de que ela não concluirá da forma do que somos o que nos é impossível conhecer ou fazer e, por isso, ainda transcendental; mas concluirá da contingência ou dos campos de experiência que nos faz ser o que somos, deficientes, a possiblidade de não mais ser, pensar e fazer o que somos ou quanto 
esboço para um pensamento da diferença e do devir deficiente na educação

ao modo como nos constituíamos, ou seja, como um exercício de ultrapassagem de nossos limites. Por fim, esse éthos filosófico deve ser entendido também como uma atitude experimental. Com isso, Foucault quis dizer que:

[...] esse trabalho realizado nos limites de nós mesmos deve, por um lado, abrir um domínio de pesquisas históricas e, por outro, colocar-se à prova da realidade e da atualidade, para simultaneamente apreender os pontos em que a mudança é possível e desejável e para determinar a forma precisa a dar a essa mudança. O que quer dizer que essa ontologia histórica de nós mesmos deve se desviar de todos esses projetos que pretendem ser globais e radicais. (2001, p. 1393-1394).

Talvez podemos ver mais claramente, com a indicação do devir deficiente como uma crítica prática, arqueológica e genealógica, e experimental do pensamento, se esboçar uma cartografia da problematização das diferenças e da deficiência no tempo presente, a qual está recoberta, em toda a sua latitude, pela problematização do próprio pensamento. O que é preciso esclarecer, ademais, é que toda essa concepção de filosofia como diagnóstico da atualidade e como ato de problematização da diferença tem a ver intrinsecamente, estando inclusive por ela compreendida, com a elaboração de uma história do pensamento. Foucault recorreu frequentemente à noção de problematização para distingui-la, no essencial, de uma história das ideias, ou seja, da análise dos sistemas de representação; e de uma história das mentalidades, isto é, da análise das atitudes e dos esquemas de comportamento. “[...] O pensamento não é o que habita uma conduta e lhe dá um sentido; é, sobretudo, aquilo que permite tomar uma distância em relação a essa maneira de fazer ou de reagir, e tomá-la como objeto de pensamento e interrogá-la sobre seu sentido, suas condições e seus fins. " (2001, p. 1416). Colocarmos, pois, a problematização das diferenças sob o signo de uma história do pensamento é, por seu turno, interessar-se, sobretudo, pela maneira com que se constituem os campos de experiência e os problemas que são colocados para o pensamento, ao mesmo tempo em que se procura discernir as estratégias com as quais são desenvolvidas as respostas possíveis. Com efeito, a um mesmo conjunto de dificuldades diversas respostas podem ser dadas; e, na maior parte do tempo, elas são efetivamente propostas. Contudo, como esclareceu Foucault, “[...] o que é preciso compreender é aquilo que as torna simultaneamente 
possíveis; é o ponto no qual se origina sua simultaneidade; é o solo que pode nutrir umas e outras, em sua diversidade, e, talvez, a despeito de suas contradições. " (2001, p. 1416-1417).

\section{Possibilidades de uma ontologia da diferença e do devir deficiente: apontamentos} finais.

A atividade de problematização do pensamento para Foucault, a qual o próprio Deleuze (1988) reconheceu desempenhar um papel central na obra filosófica de seu conterrâneo, ele também a desenvolveu em sua filosofia; mas de um modo independente daquele outro. Merece destaque o trabalho sobre a obra literária de Marcel Proust, em particular sobre a emissão e a interpretação dos signos tais como eles se apresentam em $\grave{A}$ la recherche du temps perdu (1999). Com efeito, o que em Deleuze parece se aprofundar em relação à Foucault é primazia atribuída aos signos, acerca de sua importância e do papel que eles desempenham na filosofia para que o pensamento seja apreendido em um duplo movimento, que é, do mesmo modo, um duplo investimento filosófico: o pensamento como problematização e como o que deve ser problematizado.

Em Proust et les signes, Deleuze (1987) desbravou um pensamento intensivo, em estado nascente. O que ele encontrou em Proust é propriamente a invenção de um espaço em que fosse, de novo, possível pensar. E a partir de um trabalho de verve filosófica acerca da literatura proustiana fez surgir, como o inesperado ou, talvez, o impensado, um devir-filósofo do escritor e um devir-literário da filosofia; enfim, a possibilidade de o exercício do pensamento se destituir de sua imagem dogmática, e de encontrar nos signos, na qualidade de acontecimentos-efeito, a criação no pensamento do ato de pensar. Ou seja, de encontrar no involuntário, talvez em certo involuntarismo da filosofia, o exercício do pensamento como problematização e experimentação: para o que esta situação colocaria a filosofia muito próxima da criação artística em relação à busca da verdade, sendo este o caso da literatura, por exemplo. Tratava-se, portanto, de uma busca mais ao modo de um trabalho experimental do pensamento, e que tinha muito pouco ou quase nada de parecido com a busca da verdade propalada por uma filosofia da 
esboço para um pensamento da diferença e do devir deficiente na educação

identidade e da representação, mas que permitiu a Deleuze (1976) formular no essencial os princípios de uma filosofia da diferença e da repetição. A importância da apresentação filosófica à literatura de Proust consistia, desse modo, em sugerir que a Recherche fosse concebida na forma de um sistema pluralista em que os diferentes tipos de signos, seus efeitos e suas relações com o sentido fossem analisados como a necessidade absoluta de um ato de pensamento.

Ao considerar esses elementos de atuação da diferença, os acontecimentosefeito, não poderíamos negligenciar o quanto a tarefa filosófica como problematização do pensamento permite recolocar em nova perspectiva a analítica do devir deficiente: não pensar pela identidade e pela representação, mas pelo signo do acontecimento; não pensar em termos de história e regularidades, tais como as classificações nosopolíticas, mas pensar os componentes geográficos, as territorialidades e os movimentos de desterritorialização do pensamento. Pensar pela diferença não é, enfim, fazer uma história da deficiência, mas uma geofilosofia ${ }^{7}$ da deficiência, isto é, pensar os agenciamentos que os acontecimentos cruzam e cartografar o devir como produção de novos modos de vida. Na direção dessa abertura de pensamento, apresentamos três alternativas finais na condição de possibilidades para se firmar na educação uma ontologia da diferença e do devir deficiente.

$1^{a}$ alternativa - Reverter o platonismo ou conquistar para o devir uma arte das superfícies. De acordo com Deleuze (1969), Platão distinguia fundamentalmente duas dimensões: a das qualidades fixas e o devir. É preciso reconhecer, contudo, que a distinção entre essas duas dimensões não ter a ver, em absoluto, com uma dualidade abstrata e vazia entre o inteligível e o sensível, por exemplo; uma vez que a história da filosofia não parou de multiplicar esses dualismos

\footnotetext{
${ }^{7}$ Esta perspectiva é bastante promissora, indicamos, para tanto, um pequeno fragmento com o qual Deleuze e Guattari iniciam a longa exposição deste tema em Qu'est-ce que la philosophie?: “O sujeito e o objeto oferecem uma má aproximação do pensamento. Pensar não é nem um fio estendido entre um sujeito e um objeto, nem uma revolução de um em torno do outro. Pensar se faz antes na relação entre o território e a terra. Kant é menos prisioneiro [do] que se acredita das categorias de objeto e de sujeito, já que sua idéia de revolução copernicana põe diretamente o pensamento em relação com a terra; Husserl exige um solo para o pensamento, que seria como a terra, na medida em que não se move nem está em repouso, como intuição originária. " (DELEUZE; GUATTARI, 1992, p. 113).
} 
indefinidamente entre quaisquer coisas que pudessem ser colocadas na relação da ordem das oposições. A dualidade platônica, ao contrário, define-se inteiramente pelo método da divisão que certifica o que pode ser pensado e que tornou possível o mundo da representação; e, no outro extremo, o que é sem lei e sem origem, o devir ilimitado, que não corresponde à designação de nenhuma identidade fixa, e da qual, poderíamos afirmar, a permanência é constantemente ameaçada pelo paradoxo deste puro devir como identidade infinita: "[...] O bom senso é a afirmação de que, em todas as coisas, há um sentido determinável; mas o paradoxo é a afirmação dos dois sentidos ao mesmo tempo." (DELEUZE, 1969, p. 09).

\footnotetext{
Platão convidava-nos a distinguir duas dimensões: $1^{\mathrm{a}}$ ) a das coisas limitadas e medidas, das qualidades fixas, quer sejam permanentes ou temporárias, mas supondo sempre freadas assim como repousos, estabelecimento de presentes, designações de sujeito: tal sujeito tem tal grandeza, tal pequenez em tal momento; $2^{\mathrm{a}}$ ) e, ainda, um puro devir sem medida, verdadeiro devir-louco que não se detém nunca, nos dois sentidos ao mesmo tempo, sempre furtando-se ao presente, fazendo coincidir o futuro e o passado, o mais e o menos, o demasiado e o insuficiente na simultaneidade de uma matéria indócil [...]. (DELEUZE, 1969, p. 09).
}

Eis aí o que, estando fora, e não no exterior desse método, que institui para o pensamento o valor e o mundo da representação, poderia causar uma violência original ao pensamento; isto é, de originá-lo por arrombamento, instituindo-lhe a necessidade absoluta de um ato de pensar, despertando uma estranheza congênita. Falamos, é claro, do puro devir e de sua identidade infinita; em uma só palavra, do acontecimento. Pensar a deficiência como devir, desse modo, é um desafio porque não é falar de qualidades mensuráveis, distribuídas, medidas segundo uma classificação biopolítica, nosopolítica, psiquiátrica ou social; antes é pensá-la através do prisma de um agenciamento polifônico dos acontecimentosefeito, que verticalizam em cada sujeito deficiente a própria deficiência, que singularizam as experiências que se fazem dos limites mais ou menos fortes impostos pela deficiência e a possibilidade renovada de ultrapassá-los, de inventar as próprias soluções. Para todos os efeitos, a possibilidade de renovação do pensamento é, do mesmo modo, a necessidade de tecer a crítica: “[...] As condições de uma verdadeira crítica e de uma verdadeira criação são as mesmas: destruição 
da imagem de um pensamento que pressupõe a si próprio, gênese do ato de pensar no próprio pensamento. " (DELEUZE, 1976, p. 182). Na verdade, ambas essas questões participam, igualmente, de um único e mesmo movimento: o de crítica e o de clínica.

Deleuze $(1969,1983)$ define o problema da representação essencialmente como uma tarefa, a reversão do platonismo. Segundo ele, Nietzsche assim havia definido a tarefa de sua filosofia, e em razão de um desdobramento que talvez ele mesmo não pudesse supor ou imaginar, tornar-se-ia, com efeito, a tarefa da filosofia do futuro. Deleuze apresenta essa tarefa filosófica em termos pouco comuns, na verdade, bastante estranhos em relação ao que podemos notar nos estudos sobre a filosofia de Platão a partir da historiografia filosófica. Ele considera, primeiramente, que essa fórmula, "reversão", é demasiado abstrata e deixa oculta a verdadeira motivação do platonismo. Qual é, então, este motivo? Deleuze oferece uma pista: “[...] Reverter o platonismo deve significar, ao contrário, tornar manifesta à luz do dia esta motivação, 'encurralar' esta motivação - assim como Platão encurrala o sofista." (1969, p. 292). A análise de Deleuze toca no essencial: a verdadeira motivação do platonismo deve ser buscada do lado de uma vontade de selecionar, de tal modo que o projeto platônico apenas se revelaria em sua inteireza e verdadeiramente quando reportado ao método da divisão.

O método da divisão consiste, pois, em uma verdadeira tarefa seletiva. Relacionando-o ao tema que analisamos, tal método é sistematicamente empregado para garantir, aos regimes de saberes científicos e pedagógicos sobre a deficiência, a ordem qualitativa das semelhanças e a ordem quantitativa das equivalências, ao mesmo tempo em que está determinado a oferecer a prova que sentenciará, à errância e ao sem-fundo, o indivíduo inclassificável; isto é, o que não pode ser pensado segunda às duas ordens da generalidade e da representação: a singularidade, o simulacro, ou o devir-louco. A diferença apenas exterior introduzida no pensamento pelo método da divisão é, nesse sentido, não uma dualidade estéril, mas o que funda o mundo da representação: a relação do 
Mesmo com o Semelhante, ou das cópias-ícones em relação ao Modelo, de onde o simulacro, o puro devir ilimitado, está excluído. A normalidade não suporta pensar a dessemelhança, tudo o que não tem uma identidade determinável intrinsecamente em relação ao modelo ou ao fundamento está condenado a permanecer do lado de fora do pensamento. Vemos ao fim e ao cabo que propor uma ontologia do devir deficiente é restituir à deficiência a diferença interna e preparar, assim, novos campos de experiências de constituição da subjetividade deficiente. Ainda sobre a diferença, Deleuze oferece uma das mais belas definições do devir, e acreditamos que esta definição possa, do interior mesmo da deficiência, operar o devir deficiente como produção de vida. Devir:

[...] são forças puras, traçados dinâmicos no espaço que, sem intermediário, agem sobre o espírito, unindo-o diretamente à natureza e à história; experimentação de uma linguagem que fala antes das palavras, gestos que se elaboram antes dos corpos organizados, máscaras antes das faces, espectros e fantasmas antes das personagens - todo o aparelho da repetição como "potência terrível". (1976, p. 19).

Pensar em termos de uma filosofia como arte das superfícies consiste, pois, em dar à operação de reversão do platonismo um segundo sentido. Se, em primeiro lugar, essa fórmula significava tornar manifesta a verdadeira motivação do platonismo, a divisão entre o que recebe a ação da Ideia e o que se subtrai a essa ação, o segundo movimento consiste em devolver o direito aos simulacros como efeitos de superfície, isto é, em colocar no primeiro plano de análise o puro devir ou o acontecimento, e de afirmar para o pensamento a sua identidade infinita.

O paradoxo deste puro devir, com a sua capacidade de furtar-se ao presente, é a identidade infinita: identidade infinita dos dois sentidos ao mesmo tempo, do futuro e do passado, da véspera e do amanhã, do mais e do menos, do demasiado e do insuficiente, do ativo e do passivo, da causa e do efeito. É a linguagem que fixa os limites (por exemplo, o momento em que começa o demasiado), mas é ela também que ultrapassa os limites e os restitui à equivalência infinita de um devir ilimitado ("não segure um tição vermelho durante demasiado tempo, ele o queimará; não se corte demasiado profundamente, isso faria você sangrar"). (DELEUZE, 1969, p. 10-11).

Contudo, se ainda não conseguimos escapar ao elemento da representação é porque permanece, para o pensamento, a dupla exigência do Mesmo e do 
Semelhante. Na realidade, não se sai facilmente da representação, uma vez que a condição a que está subsumido o pensamento é a de uma imagem dogmática que impede perfeitamente que a singularidade surja no pensamento, que a gênese do ato de pensar possa ser engendrada no pensamento, que a criação no pensamento seja mais uma vez possível. “[...] Simplesmente, o Mesmo encontrou um princípio incondicionado capaz de fazê-lo reinar no ilimitado: a razão suficiente; e o Semelhante encontrou uma condição capaz de aplicá-lo ao ilimitado: a convergência ou a continuidade. " (DELEUZE, 1969, p. 299). Quanto a Deleuze (1976), a sua crítica toca mais uma vez no essencial: é preciso retirar a diferença de seu estado de maldição. E para o objetivo de pensar o devir deficiente na educação, é preciso primeiro restituir à deficiência a diferença preterida em favor de uma prática nosopolítica que separa, classifica e normatiza os deficientes.

$2^{a}$ alternativa - Posto esse desafio mais geral, outra possibilidade emerge no sentido de pensar na educação uma ontologia do devir deficiente: propor que a reorganização do trabalho pedagógico da escola inclusiva se inscreva no domínio das práticas, isto é, na orientação de que tanto os discursos como as práticas pedagógicas sejam admitidos como práticas de constituição da subjetividade. Portanto, uma atitude crítica em face do desafio de superar a racionalidade instrumental que pesa sobre a escola inclusiva poderia partir, inicialmente, de uma dissolução da dicotomia imposta às práticas e aos saberes pedagógicos. É frequente inclusive encontrar nos cursos de formação de professores a reiteração da dicotomia entre práticas pedagógicas, o plano dos fatos, e saberes pedagógicos, o plano dos modelos ou teorias. A distinção é tal que a educação é tratada numa ambivalência que idealmente deveria se resolver na ação pedagógica concreta, mas que não passa, na verdade, de uma solução hipotética. Tal dialética é apenas negativa, porque recobre a distinção entre teoria e prática de uma síntese ideal que subtrai de ambas as partes a diferença real irredutível ao regime do geral ou do absoluto, pretensamente universais. De outro modo, o que vemos replicado é o decalque do projeto platônico da dualidade, definido inteiramente pelo método da divisão. Não se trata, é claro, como esclarecemos a pouco, de uma dualidade 
abstrata e vazia entre o inteligível e o sensível, por exemplo, mas da instauração de uma ordem de seleção e oposições que define dialeticamente o que recebe a ação da Ideia, as coisas limitadas e medidas, e o que se subtraia a esta ação, o puro devir ou a diferença qualitativa. Tratava-se, é claro, para Platão de instaurar a diferença nas dualidades colocadas em série, contudo uma diferença tornada apenas exterior, ou seja, tomada apenas em relação de exterioridade.

Mas, o que isso tem a ver com a análise que propomos? Pensamos que há certa atualidade no modo como a potência dialética da divisão incide no problema que analisamos. Basta considerarmos outra vez mais a dualidade reiterada entre ação pedagógica e teoria pedagógica, entre o plano da prática e o plano teórico. Com pouca variação entre os casos, o que vemos posto é a definição da teoria como o momento de criação conceitual, plano de composição da realidade que assume a forma ideal. Noutro lado, o mundo da prática, plano de realização do conceito, de encarnação ou de efetuação da ideia. Mas tal dialética precisaria ser bem ajustada, porque a realização da ideia depende de um plano de coordenadas que falta à intelecção ou ao conceito, e que só pode ser encontrado no plano das ações; mas que, paradoxalmente, é regulado pelo valor e pela verdade imanentes à ideia, e não à prática. É exatamente por isso que o problema analisado é, de alguma forma, o problema de propor uma dialética, cuja síntese, permanecendo apenas ideal, renuncia a experiência em favor de uma verdade formal.

Indicamos uma solução possível para este impasse. Mas ela não poderia caminhar ao lado de uma razão dialética, precisará partir de outro lugar, quer dizer, alhures. Esta outra concepção é compreender a ação e a teoria pedagógicas como pertencentes ao domínio das práticas. Isto significa, primeiramente, que a propositura de uma solução não pode consistir na resolução da dicotomia entre prática e teoria; na verdade, não deve partir dela. Para uma filosofia da educação contemporânea, para a qual é imperativo abordar o problema da deficiência e do devir deficiente, julgamos ser relevante destacar aqui o domínio de análise das práticas tal qual apresentado por Michel Foucault (1966, 1969, 1984, 1994a, 1994b, 1994c, 2001). 
Consoante à obra do filósofo, no caso, por exemplo, dos conceitos episteme e dispositivo, é possível inferir que o domínio de análise de Foucault são as práticas. O primeiro se refere às chamadas práticas discursivas, e o segundo, às práticas não discursivas. Em termos bibliográficos, Les mots e les choses (1966) e L'Archéologie du savoir (1969) representam o período dos estudos arqueológicos, para o qual o conceito de episteme ocupava a cena principal. Isto quer dizer, em outras palavras, que a episteme era o objeto de uma descrição arqueológica e dos problemas metodológicos colocados por ela. É complementar deste argumento o que podemos ler em Réponse à une question, conforme o que segue:

[...] Em lugar de ocupar-se de uma história econômica, social, política, envolvendo uma história do pensamento [...], em lugar de ocupar-se de uma história das ideias que faria referência (seja por um jogo de signos e expressões, seja pelas relações de causalidade) às condições extrínsecas, haveria que ocupar-se de uma história das práticas discursivas nas relações específicas que as articulam com outras práticas. [...]. (FOUCAULT, 1994a, p. 686-687).

Neste texto, entendemos que o dispositivo aparece como objeto de análise em face da premência de incluir as práticas não discursivas, isto é, as relações de poder, entre as condições de possiblidade de formação dos saberes. Nesse sentido, os dispositivos integrariam tanto as práticas discursivas como aquelas não discursivas. Citam-se, à título de exemplo, os dispositivos disciplinares, dispositivos de poder, dispositivos carcerários, dispositivos de sexualidade, dispositivos de verdade, entre outros. Foucault (1994b) reconheceu, desse modo, a relevância da análise do poder na relação entre o discursivo e o não discursivo.

No conjunto, podemos dizer que o domínio das práticas compreende, para Michel Foucault, o arco que se estende da ordem do saber à ordem do poder, e ambas ao domínio das práticas de constituição da subjetividade. Portanto, embora Foucault não o tenha determinado conceitual e separadamente, podemos afirmar que o filósofo utilizou o conceito de prática desde as primeiras de suas obras. Mais três exemplos poderiam se somar ao escopo pretendido. No texto Qu'est-ce que les Lumières? (2001, p. 1498-1507), Foucault apresenta uma ideia bastante original: a de considerar a Modernidade como um éthos, isto é, como uma atitude. Tal atitude consiste numa série de investigações arqueológicas e genealógicas das práticas que 
constituem historicamente os indivíduos, tal como comentávamos anteriormente.

Outro texto relevante é L'usage des plaisirs (1984), em cuja introdução se lê a história da sexualidade não como uma história dos comportamentos ou das representações, mas de uma experiência; entendendo por esta palavra: “[...] a correlação, em uma cultura, entre domínios de saber, tipos de normatividade e formas de subjetividade. " (p. 10). Um último texto a indicar é Préface à l'Histoire de la sexualité (1994c). Nele, Foucault interpreta a análise histórica das formas de experiência em termos de pensamento, fazendo destacadamente uma indicação do uso do conceito de prática:

[...] Por "pensamento" entendo o que instaura, em diferentes formas possíveis, o jogo do verdadeiro e do falso e que, por consequência, constitui o ser humano como sujeito de conhecimento; o que funda a aceitação ou a recusa da regra e constitui o ser humano como sujeito social e jurídico; o que instaura a relação consigo mesmo e com os outros, e constitui o ser humano como sujeito ético.

Assim entendido, não há que buscar o pensamento somente nas formulações teóricas, como as da filosofia ou da ciência; ele pode e dever ser analisado em todas as maneiras de dizer, de fazer, de se conduzir, nas quais o indivíduo se manifesta e age como sujeito de conhecimento, como sujeito ético ou jurídico, como sujeito consciente de si e dos outros. Neste sentido, o pensamento é considerado como a forma mesma da ação, como a ação na medida em que ela implica o jogo do verdadeiro e do falso, a aceitação ou a recusa da regra, a relação consigo mesmo e com os outros. O estudo das formas de experiência poderá então se fazer a partir de uma análise das "práticas" discursivas ou não, se se designa por isso os diferentes sistemas de ação na medida em que sejam habitados pelo pensamento assim entendido. (1994c, 579-580).

Está claro, porém, que para o desafio de pensar o trabalho da escola inclusiva no registro das práticas não há soluções encontradas, elas devem ser construídas. É por essa razão, também, que o problema não se limita à análise das políticas públicas de inclusão, mas requer uma análise das práticas discursivas e não discursivas que funcionam como operadores de inclusão ou de exclusão nas escolas. É relevante, portanto, a indicação encontrada no trabalho de Foucault, que, ao fazer da pesquisa um tipo de jornalismo filosófico, recobre a amplitude e a latitude dos elementos estudados sob o domínio das práticas. Especialmente o último fragmento apresentado ampara a proposição que firmamos aqui. Em resumo, propor um estudo das formas de experiência da deficiência a partir da análise das práticas discursivas e não discursivas é investigar as formas de 
regularidade que organizam as maneiras de dizer, de fazer, de conduzir-se na vida deficiente; sua generalidade (leia-se recorrência) e as configurações historicamente singulares que fazem do devir deficiente não uma formulação teórica, mas uma analítica da experiência.

$3^{a}$ alternativa - Pensar a ontologia do devir deficiente sob o signo do acontecimento. No afã de implantar no ensino escolar as políticas públicas de inclusão, relega-se a um segundo plano algo de mais fundamental às práticas inclusivas: a questão das diferenças. Sob a égide homogeneizante da sociedade normalizada, reduz-se a relação constitutiva da diferença a mera aceitação e respeito ao diferente, trabalhando exaustivamente na direção de superar a diferença como desigualdade entre o normal e o deficiente. O que não se analisa claramente é que, ao agir assim, relega-se a diferença ao esquecimento, à errância, ao obliterado lugar do inominável. A palavra de ordem é: a diferença deve ser trabalhada, escrutinizada, controlada nas atividades e no tempo; enfim, deve-se normalizá-la, pois só assim a diferença teria lugar na sociedade dos vivos. O problema é que a normalização como causa e processo não está problematizada, ela já está demasiado enraizada nas convicções morais e, por que não dizer, científicas e pedagógicas da sociedade moderna. Alcança-se, assim, a segunda palavra de ordem: deve-se elevar as diferenças à estatura do idêntico, das representações sociais aceitas; enfim, deve-se salvar o diferente de si mesmo. Triste fim de uma sociedade normalizada, que ao não admitir o diferente, anula-o.

$\mathrm{E}$ as críticas não param por aí. Contudo, as soluções também não estão prontas, elas devem ser inventadas, construídas por diferentes estratégias e a muitas mãos. Um belo exemplo, nesse sentido, é o Dossiê "Didáticas para as diferenças", publicado na Revista Pro-Posições, vol. 26, n. 1, jan./abr. de 2015. Na Apresentação, o organizador Alexandre Filordi de Carvalho analisa conjuntamente os seis artigos que compõem o dossiê, apontando para o eixo principal em torno ao qual giram as várias frentes de problematização das diferenças: "[...] a problematização das diferenças vem se consolidando como instrumento a nos desafiar a pensar e a agir com os outros que andam ao nosso 
lado. " (2015, p. 24). E acrescentou acertadamente: “[...] o conjunto dos textos aqui presentes assinalam para os desafios que a educação contemporânea tem diante de si: aprender a manejar a diferença como afirmação da própria diferença. " (p. 24). Eis aí a indicação que pode servir de insight para a análise das práticas e das ideias de inclusão na educação: trata-se de não mais pensar em termos de Didática, mas em didáticas particulares, específicas, haja vista a multiplicidade que habita os diferentes, tanto na esfera do comum como no singular.

Em filosofia da educação, a análise do conceito acontecimento é imprescindível para um aprofundamento da problematização das diferenças. Pensar a educação sob a figura do acontecimento é investir na constituição de campos de experiência tanto quanto realizar, ao modo de Foucault, a ontologia crítica de nós mesmos, isto é, a ontologia histórica da constituição de nossa subjetividade. Necessita de investigar, segundo Eugénia Vilela e Fernando Bárcena (2006), três dimensões da experiência educativa ligadas à intensidade dessa noção: um acontecimento é o que dá a pensar, não aquilo sobre o qual devemos pensar, mas o que nos dá a possibilidade de pensar sob a exigência de um pensamento novo e criativo; é o que nos permite fazer uma experiência, com a condição de que o pensamento seja verdadeiramente uma experimentação, mas também uma problematização de nossos modos de existência; e é o que rompe a continuidade do tempo, permitindo surgir das cisões e brechas a experiência de um tempo intensivo e de durações muito diferentes que modificam as subjetividades.

[...] De acordo com esta caracterização, abordar a análise da educação como figura do acontecimento significa repensar o que, desde o ponto de vista do mundo da vida, configura a experiência humana do aprender. Sendo aquilo que nos dá a pensar, a educação é a experiência da aprendizagem do novo, do inédito, do estranho. Sendo aquilo através do qual se faz experiência em nós, a educação é a experiência da aprendizagem do padecer, da paixão. E, finalmente, por ser o que rompe a continuidade do tempo, a educação é a experiência da aprendizagem da decepção e de um certo desencanto. (VILELA; BÁRCENA, 2006, p. 18).

Vemo-nos, pois, diante de um desafio, o qual não nos parece ser proposto pelo desenvolvimento natural de nossos argumentos e questões, mas como vindo de fora, posto do exterior, talvez com a insistência de um devir-outro que avança em direção ao nosso trabalho para, no momento seguinte, despojá-lo de suas 
certezas e convicções. É, assim, um ponto de desestabilização. Precisamos ver claramente que o que é mais importante à proposta da atividade filosófica como problematização, como diagnóstico da atualidade, enfim, como éthos e atitude crítica diante das ocorrências da vida e das provocações ao pensamento é a experiência, o pensamento como experimentação. Precisamos fazer primeiro, na verdade, no tocante à deficiência, a mesma pergunta do poeta com que aquele Dossiê foi aberto: “Quem é o outro que sempre anda ao teu lado? " (ELIOT, 2004, 163).

\section{Referências}

BARROS, Manoel de. Menino do mato. Rio de Janeiro: Alfaguara, 2015.

CARVALHO, Alexandre Filordi de. Apresentação. Dossiê didáticas para as diferenças. Pro-Posições, Campinas, vol. 26, n. 1 (76), p. 23-28, jan./abr. 2015. Disponível em: <http://www.scielo.br/pdf/pp/v26n1/0103-7307-pp-26-010023.pdf>. Acesso em: 30 jul. 2016.

CARVALHO, Alexandre Filordi de. Governo da infância e ontologia política do devir deficiente: implicações para a educação [Internet]. In: VII Colóquio Internacional de Filosofia da Educação, 2014, Rio de Janeiro. Anais eletrônicos. Rio de Janeiro: UERJ, 2014. p. 01-15. Disponível em: http:// www.filoeduc.org/trabalhos_2014/TR377.pdf

DELEUZE, Gilles. Conversações, 1972-1990. Rio de Janeiro: Ed. 34, 1992.

DELEUZE, Gilles. Crítica e clínica. São Paulo: Ed. 34, 1997.

DELEUZE, Gilles. Différence et répétition. Paris: Presses Universitaires de France, 1976.

DELEUZE, Gilles. Empirismo e subjetividade: ensaio sobre a natureza humana segundo Hume. São Paulo: Ed. 34, 2001.

DELEUZE, Gilles. Foucault. São Paulo: Brasiliense, 1988.

DELEUZE, Gilles. Logique du sens. Paris: Éditions de Minuit, 1969.

DELEUZE, Gilles. Nietzsche et la philosophie. 6 ed. Paris: Presses Universitaires de France, 1983.

DELEUZE, Gilles. Proust e os signos. Rio de Janeiro: Forense Universitária, 1987.

DELEUZE, Gilles; GUATTARI, Félix. Mil platôs - capitalismo e esquizofrenia. vol. 4. São Paulo: Ed. 34, 1997. p. 11-113.

DELEUZE, Gilles; GUATARRI, Félix. O que é filosofia? Rio de Janeiro: Ed. 34, 1992.

ELIOT, Thomas Stearns. Poesia. (Obras completas, Vol. 1). São Paulo: ARX, 2004. 
FOUCAULT, Michel. Em defesa da sociedade: curso no Collège de France (19751976). São Paulo: Martins Fontes, 1999.

FOUCAULT, Michel. Histoire de la sexualité II: L'usage des plaisirs. Paris: Éditions Gallimard, 1984.

FOUCAULT, Michel. L'Archéologie du savoir. Paris: Éditions Gallimard, 1969.

FOUCAULT, Michel. L'écriture de soi. In: DEFERT, Daniel; EWALD, François; LAGRANGE, Jacques (Eds.). Dits et écrits II: 1976-1988. Paris: Éditions Gallimard, 2001. p. 1234-1249.

FOUCAULT, Michel. Le jeu de Michel Foucault. In: DEFERT, Daniel; EWALD, François; LAGRANGE, Jacques (Eds.). Dits et écrits, vol. 3 - 1976-1979. Paris: Éditions Gallimard, 1994b, p. 298-329.

FOUCAULT, Michel. Le souci de la vérité. In: DEFERT, Daniel; EWALD, François; LAGRANGE, Jacques (Eds.). Dits et écrits II: 1976-1988. Paris: Éditions Gallimard, 2001. p. 1487-1497.

FOUCAULT, Michel. Les mots et les choses: une archéologie des sciences humaines. Paris: Éditions Gallimard, 1966.

FOUCAULT, Michel. Nascimento da biopolitica: curso no Collège de France (19781979). São Paulo: Martins Fontes, 2008a.

FOUCAULT, Michel. Os anormais: curso no Collège de France (1974-1975). São Paulo: Martins Fontes, 2001.

FOUCAULT, Michel. Polémique, politique et problématisations. In: DEFERT, Daniel; EWALD, François; LAGRANGE, Jacques (Eds.). Dits et écrits II: 1976-1988. Paris: Éditions Gallimard, 2001. p. 1410-1417.

FOUCAULT, Michel. Préface à l'Histoire de la sexualité. In: DEFERT, Daniel; EWALD, François; LAGRANGE, Jacques (Eds.). Dits et écrits, vol. 4 - 1980-1988. Paris: Éditions Gallimard, 1994c, p. 578-584.

FOUCAULT, Michel. Qu'est-ce que les Lumières?. In: DEFERT, Daniel; EWALD, François; LAGRANGE, Jacques (Eds.). Dits et écrits II: 1976-1988. Paris: Éditions Gallimard, 2001. p. 1498-1507.

FOUCAULT, Michel. Réponse à une question. In: DEFERT, Daniel; EWALD, François; LAGRANGE, Jacques (Eds.). Dits et écrits, vol. 1 - 1954-1969. Paris: Éditions Gallimard, 1994a, p. 673-695.

FOUCAULT, Michel. Segurança, território, população: curso dado no Collège de France (1977-1978). São Paulo: Martins Fontes, 2008b.

FOUCAULT, Michel. Table ronde du 20 mai 1978. In: DEFERT, Daniel; EWALD, François; LAGRANGE, Jacques (Eds.). Dits et écrits II: 1976-1988. Paris: Éditions Gallimard, 2001. p. 842-844. 
FOUCAULT, Michel. Une esthétique de l'existence. In: DEFERT, Daniel; EWALD, François; LAGRANGE, Jacques (Eds.). Dits et écrits II: 1976-1988. Paris: Éditions Gallimard, 2001. p. 1549-1554.

FOUCAULT, Michel. What is Enlightenment? In: DEFERT, Daniel; EWALD, François; LAGRANGE, Jacques (Eds.). Dits et écrits II: 1976-1988. Paris: Éditions Gallimard, 2001. p. 1381-1397.

KANT, Immanuel. Crítica da razão pura. 5. ed. Lisboa: Fundação Calouste Gulbenkian, 2001.

PROUST, Marcel. À la recherche du temps perdu. Paris: Éditions Gallimard, 1999. (Collection Quarto).

RANCIÈRE, Jacques. O mestre ignorante - cinco lições sobre a emancipação intelectual. 2 ed. Belo Horizonte: Autêntica, 2007.

REVEL, Judith. Le vocabulaire de Foucault. Paris: Édition Ellipses, 2009.

SPINOZA, Benedictus de. Ética (Edição Bilíngue). 3 ed. Belo Horizonte: Autêntica, 2010 .

VILELA, Eugénia; BÁRCENA, Fernando. Acontecimento. In: CARVALHO, Adalberto. Dias. (Coord.). Dicionário de filosofia da educação. Porto: Porto Editora, 2006. p. 14-19.

WORLD HEALTH ORGANIZATION. World report on disability. Malta: WHO Library Cataloguing-in-Publication Data, 2011. 